\title{
A NEW SCALING STRATEGY OF BUBBLING FLUIDIZED BED REACTORS BASED ON POPULATION-BALANCE MODEL
}

\author{
Robert Macias $^{1}$, Juan Maya ${ }^{1}$, Farid Chejne ${ }^{1}$, Carlos Londoño ${ }^{1}$, and Javier De La Cruz ${ }^{1}$ \\ ${ }^{1}$ Universidad Nacional de Colombia Sede Medellin
}

November 21, 2021

\begin{abstract}
This work proposes a new strategy for the scaling of bubbling fluidized bed reactors. This strategy is based on the bubble size distribution, bubble coalescence phenomenon, and the chemical reactivity, allowing to deduct the dimensionless number Chejne-Macias-Maya that must remain constant at different scales to guarantee the fluidization regime. The proposed strategy is validated from computational simulations carried out at different operating conditions. Additionally, limits for the validity of this scaling strategy were determined, which agrees with those reported in the literature.
\end{abstract}

\section{Hosted file}

A NEW SCALING STRATEGY OF BUBBLING FLUIDIZED BED REACTORS BASED ON POPULATION.docx available at https://authorea.com/users/327056/articles/546355-a-new-scaling-strategy-ofbubbling-fluidized-bed-reactors-based-on-population-balance-model 